Bates College

SCARAB

$6-1-2020$

\title{
The Role of Attitudes, Social Norms, and Perceived Behavioral \\ Control as Factors Influencing Urban and Suburban Residential Adoption of Stormwater Best Management Practices
}

\author{
Francis R. Eanes \\ Bates College, feanes@bates.edu \\ Xiaoqing Zhou \\ Bates College
}

Follow this and additional works at: https://scarab.bates.edu/faculty_publications

\section{Recommended Citation}

Eanes, F.R., and Zhou, X. (2020) The Role of Attitudes, Social Norms, and Perceived Behavioral Control as Factors Influencing Urban and Suburban Residential Adoption of Stormwater Best Management Practices. Environmental Management. 65, 737-747. https://doi.org/10.1007/s00267-020-01286-5

This Article is brought to you for free and open access by the Departments and Programs at SCARAB. It has been accepted for inclusion in All Faculty Scholarship by an authorized administrator of SCARAB. For more information, please contact batesscarab@bates.edu. 
The Role of Attitudes, Social Norms, and Perceived Behavioral Control as Factors Influencing Urban and Suburban Residential Adoption of Stormwater Best Management Practices

Authors: *Francis R. Eanes ${ }^{1}$, Xiaoqing Zhou ${ }^{1}$

${ }^{1}$ Environmental Studies Program

Bates College

7 Andrews Rd

Lewiston, ME

USA

\begin{abstract}
:
Non-point source pollution conveyed by stormwater in urban areas poses a significant threat to quality of waterbodies in the US. In the absence of systematic regulations on household stormwater management, municipalities rely largely on educational programs to encourage voluntary adoption of lawncare best management practices (BMPs) by residents that slow down and temporarily capture excess stormwater and filter out pollutants entering waterways. The current literature on factors influencing urban dwellers' adoption of lawncare BMPs mostly focuses on demographics, barriers to adoption and effectiveness of education and outreach programs. This study applies the reasoned action approach (RAA) behavioral theory to investigate how the combination of individuals' attitudes, social norms, and perceived behavioral control may affect their decision to adopt three lawncare BMPs, including mulching and fertilizer/pesticide avoidance, and support a municipal ban on lawncare chemicals. We use survey data $(\mathrm{n}=235)$ from residents in two neighboring cities in central Maine, USA. We found that perceived behavioral control predicted fertilizer/pesticide avoidance and mulching, and that beliefs and attitudes towards the outcomes of adopting lawncare BMPS was positively associated with mulching and support for a municipal ban on lawncare chemicals. We observed statistically significant but inconsistent associations between several independent variables -- including descriptive and injunctive social norms, gender, level of education, age, and homeownership status -- and our dependent variables of interest. The findings provide insights into an underexplored set of factors and confirmatory evidence for previously tested factors influencing urban residents' BMP adoption, and suggest new strategies and communication frames for environmental managers and researchers.
\end{abstract}

\title{
Key Words:
}

urban stormwater management

Reasoned Action Approach

lawncare Best Management Practices

social norms

perceived behavioral control

nonpoint source pollution

*Corresponding Author:

Francis Eanes

Environmental Studies Program

Bates College

7 Andrews Rd

Lewiston, ME

USA

Email: Feanes@bates.edu

Phone: 207-786-8268

ORCID: 0000-0002-9484-7530

Acknowledgements: (people, grants, funding)

This project was made possible by conceptual contributions of the Androscoggin Valley Stormwater Working Group (AVSWG) in Lewiston and Auburn (Maine, USA). 


\section{Introduction}

Non-point source (NPS) pollutants conveyed by urban stormwater runoff pose one of the greatest threats to water quality in waterbodies such as rivers, lakes and ground water reservoirs (Rissman and Carpenter 2015). Extensive impermeable surfaces in urban areas pave the way for large amount of stormwater to carry pollutants from roofs, roads and lawns into local waterbodies through storm drains, without being filtered by the natural landscape (National Research Council 2009). Many major pollutants of this kind come from the distribution and maintenance of public urban infrastructures such as road salt, sediments, and chemicals from motor vehicles (ibid). However, following rapid suburbanization and the proliferation of input-intensive turfgrass lawns in the decades following WWII, the export of excess nutrients (e.g. nitrogen) and pesticides constitutes one of the largest sources of nonpoint source pollution in urban watersheds (Milesi et al., 2005).

The primary regulatory regime for mitigating nonpoint source pollution -- including runoff from urban/suburban lawns -- is the by the Clean Water Act's Municipal Separate Storm Sewer System (MS4) stormwater management program, which applies to urban areas whose (partially) separated stormwater and sewer infrastructure generates surface runoff that is not treated by the sewer system(US EPA 2017). Among other programmatic components, MS4 permits require municipalities to implement and monitor stormwater pollution prevention measures, which often including outreach and education programs and materials designed to persuade individual residents to adopt stormwater-friendly best management practices (BMPs) that slow down and temporarily capture excess stormwater and filter out pollutants entering waterways (US EPA 2017). Lawncarerelated stormwater BMPs include replacing turfgrass with deeply rooted native plants, mulching turfgrass clippings when mowing to retain nutrients, , and minimizing or avoiding the application of lawn fertilizers and pesticides (National Research Council 2009). When adopted widely and efficiently in both residential and commercial areas, significant benefits can accrue both on-site, such as increased biodiversity, and downstream, such as improved water quality and increased recreation opportunities (Hottenroth et al. 1999; Turton et al. 2009). Although a diffuse array of actors and forces -- including advertisements and salespeople associated with the turfgrass industry -- have been shown to influence urban/suburban lawncare behavior (Robbins 2012; Fraser et al. 2013), the everyday task of mitigating nonpoint source pollution, including from lawns, in MS4 communities falls to small municipal committees and working groups tasked with MS4 permit compliance (US EPA 2017). Although MS4 stormwater programs ultimately rely on individual urban/suburban residents to voluntarily adopt lawncare BMPs, MS4 committees and working groups may be staffed by individuals with high proficiency in stormwater engineering 
and/or regulatory compliance, but little expertise with social-psychological drivers of lawncare behavior. In light of this potential mismatch, this study focuses on determinants of individual-level behavior, while recognizing the importance and influence of broader structural and socio-political factors.

There is a wealth of multidisciplinary literature exploring motivations for rural dwellers and farmers to adopt BMPs to protect downstream water, especially for agricultural watersheds (see Prokopy et al. 2008) Comparatively, little has investigated why urban dwellers might alter their behavior to improve urban water quality. The few studies that have examined motivations for BMP adoption among urban populations have tended to focus on socio-demographic or BMP-awareness variables to explain adoption behavior (e.g. Maeda et al. 2018; McCann and Shin 2018; Shin and McCann 2018a; Shin and McCann 2018b). Others have sought to measure the effectiveness of specific BMP education or outreach initiatives (e.g. Busse et al. 2015; Dietz et al. 2004; Leslie 2015). Largely absent from this admittedly small body of scholarship is any consistent application of common behavioral theories (e.g. theory of planned behavior, or the reasoned action approach). As a result, few have investigated how the combination of individuals' social norms and networks, environmental attitudes, and perceived behavioral control may affect their decision to adopt (or not) relevant practices, despite evidence that these factors have been shown to influence pro-environmental behavior in other domains (Prokopy et al. 2008). Consequently, this study applies Fishbein and Ajzen's (2010) Reasoned Action Approach (RAA) theory to a random-sample household survey in two small cities in Maine, USA, to better understand determinants of urban/suburban residents' adoption of stormwater-friendly lawncare BMPs. Specifically, we were interested in understanding the role that RAA components -- i.e., beliefs and attitudes towards lawncare BMP outcomes, social norms, and individual's perceived ability to adopt lawncare BMPs -- play in urban/suburban residents' reported adoption of BMPs.

\section{Literature Review}

\section{Theoretical Framework}

Our study draws on the Reasoned Action Approach, a psychological framework used to predict individuals' volitional behavior (Fishbein and Ajzen 2010). Formerly called the Theory of Planned Behavior, the RAA has been widely applied to predict health-related behaviors, anti-social behaviors (e.g. tax evasion), and all manner of proenvironmental behaviors, such as recycling (ibid). The theory posits that the combination of beliefs and attitudes towards a behavior, social norms, and perceived behavioral control predict an individual's intention to adopt the behavior, which itself directly predicts actual behavior adoption (ibid). Since the RAA has been used in a tremendously broad spectrum of pro-environmental behavioral contexts, and furthermore, since the relative effect of 
the theory's constituent parts vary tremendously based on the behavior in question, a generalized accounting of previous RAA empirical findings is neither practical nor within the scope of this study. However, the general components of the RAA include both beliefs about the outcomes of the behavior, as well as an attitudinal evaluation of the importance of these outcomes to the individual (Fishbein and Ajzen 2010). Social norms include both descriptive norms - i.e. whether or not individuals observe others adopting the behavior - as well as injunctive (or prescriptive) norms - i.e. whether individuals believe that others think they (the original individual) ought to adopt the behavior (ibid). Finally, perceived behavioral control is a construct that measures an individual's assessment of her/his ability to successfully adopt the behavior in question (ibid). Conceptually, successful outreach and education programs aimed at changing individuals' behavior will deliver messages that target individuals' attitudes, beliefs, and perceptions of social norms. Likewise, successful incentive programs may attempt to increase individuals' perceived behavioral control and/or lower any real or perceived barriers to behavior adoption.

Factors influencing the adoption of water quality and lawncare BMPS

A wealth of literature has investigated rural dwellers' - particularly farmers' - motivation to adopt practices that protect downstream water quality in agricultural watersheds (see Prokopy et al. 2008). However, there has been comparatively fewer scholarly works directed towards urban dwellers' adoption of stormwater BMPs -particularly those related to lawncare -- despite the increasing influence of runoff from urban/suburban lawns on regional water quality. In recent years, there has been a rise of scholarly interest in this area, led by Brown and Farrelly's (2009) systematic review of 53 studies investigating barriers to implementing sustainable urban water management. Among the twelve barriers they have identified, the "significant majority ... relate to 'interorganizational capacity' and 'external rules and incentives," underscoring the institutional and structural aspects of urban stormwater management (Brown and Farrelly 2009, 344). The majority of research on urban dwellers' adoption of stormwater BMPs, specifically those connected to lawncare, focuses on its incentives and motivators. One of the most powerful predictors of adoption is general knowledge of BMPs and of the environment, which includes high levels of self-reported general environmental knowledge, and knowledge about BMPs' environmental benefits, costs, maintenance, functionality of green spaces, and even gardening and lawn skills (Brehm et al. 2013; Brown et al. 2013; Busse et al. 2015; Gao et al. 2016; Gao et al. 2018; Maeda et al. 2018; Martini and Nelson 2015; McCann and Shin 2018; Persaud et al. 2016; Shin and McCann 2018a; Shin and McCann 2018b). For example, Brehm et al. (2013) find that broad knowledge of BMPs is the factor most positively linked to adoption and the only predictor of fertilizer use among residents in the Chicago (Illinois, USA) suburbs. Educational and outreach 
programs are identified by some to be an effective tool in increasing residents' knowledge on BMPs and general environmental awareness (Busse et al. 2015; Dietz et al. 2004) while exhibiting low or varied effectiveness by others (Hayden 2014; Leslie 2015). Another finding linked to this discussion is that current adopters tend to have more positive attitudes towards BMPs and are more likely to support their implementation (Gao et al. 2018). In a crossstate survey of 1,066 homeowners, Suh et al. (2016) emphasized the importance of social norms; BMP adopters were more likely than non-adopters to value neighbors' decisions on stormwater management, were more likely to have been encouraged by a neighborhood association to adopt, and held more positive perceptions of their own neighborhood's landscaping. Reduced stormwater charges (fees levied on residents and business to fund municipal stormwater management) also promote adoption as an incentive policy (Gao et al. 2016). Although comparatively under-explored in other studies, Hayden (2014) found that lawn aesthetics is an absolute priority for many homeowners when it comes to making lawn-care decisions. These findings are consistent with Fraser et al. (2013), who additionally highlighted the significant role that neighborhood-level and homeowner association covenants play in lawncare decision making and behavior.

Several demographic variables are often included alongside attitudinal factors in models attempting to predict urban/suburban residents' adoption of stormwater BMPs. Studies have consistently found that homeowners have higher BMP-adoption rates than renters or members of homeowner associations (Gao et al. 2016; Maeda 2017; Maeda et al. 2018). Besides home ownership, there is little consensus for other background factors. A few studies find that higher levels of education usually indicate higher adoption rates (e.g. Gao et al. 2016; Newburn et al. 2014), although McCann and Shin's (2018) investigation of organic fertilizer adoption found that "those with two years of college were more likely to adopt than those with a four-year degree." Income, similarly, appears to have inconsistent relationships and relatively weak associations with BMP adoptions in many studies (Newburn et al. 2014; Shin and McCann 2018a). McCann and Shin (2018) found in one study that only two income groups show correlation with BMP implementation and in another study, they find groups with household income of $\$ 50,000$ $\$ 75,000$ were more likely to adopt than those with an income of $\$ 75,000-100,000$. Few studies include the size of a home's or property's footprint (e.g. square meters) as a factor for investigation, with the exception of Gao et al. (2016) who found that homeowners of property over 1 acre are more likely to adopt BMPs than homeowners on smaller lots. 


\section{Methods}

Study Context

This study is a result of close collaboration with the Androscoggin Valley Stormwater Working Group (AVSWG) in central Maine, USA. The AVSWG is the multi-partner governance unit that maintains the MS4 permit for four municipalities (Lewiston, Auburn, Lisbon, and Sabbatus) within the Androscoggin River watershed. These municipalities are located along the Androscoggin River, which drains into Merrymeeting Bay and ultimately the Gulf of Maine. In the wake of European settlement and displacement of the Wabanaki indigenous peoples, the adjacent cities of Lewiston and Auburn (with a current combined population of 60,000) followed an industrial developmental trajectory consistent with other mill- and textile-dependent towns and cities in the northeast US (Judd 1990). Industrial production relied on the river for hydropower and as a means for disposing of wastes, such that the Androscoggin was considered one of the country's ten most-polluted rivers and the inspiration for the Clean Water Act (CWA) of 1972, championed by then-Maine Senator Edmund Muskie (ibid). Although the decades-long decline of industrial production coupled with the CWA's regulation of pollution point sources has considerably improved water quality in the river, nonpoint source pollution - chiefly stormwater-conveyed pollutants from urban/suburban lawns - remains a driver of water quality impairments (Androscoggin River Watershed Council 2016).

\section{Survey Design and Variable Descriptions}

The survey consisting of 32 questions was developed in consultation with members of the AVSWG, who as part of their next 5-year MS4 permit, needed to assess the impact of past outreach and education efforts to residents about lawncare BMPs. The survey included dependent variables that measured respondents' self-reported use of lawncare BMPs, background demographic and residential property characteristics, impact of prior AVSWG outreach and education materials ${ }^{1}$, and Lickert-scale items consistent with RAA components, including attitudes, social norms, and perceived behavioral control associated with lawncare BMPs (see Table 1). The survey was pretested with two local residential lawn owners, and revised — based on their feedback — to make some questions clearer.

Three dependent variables measured respondents' adoption of two lawncare BMPs and support for a municipal ban on lawncare fertilizer and pesticides, respectively. Lawncare BMPs included the frequency with which respondents apply fertilizers and pesticides to their lawn, and the frequency that respondents mulch (as opposed to bag and remove) their grass clippings when mowing, and were adapted from those developed through

${ }^{1}$ Due to a survey printing error, the survey questions designed to measure the impact of past AVSWG outreach materials were not valid and thus excluded from our analyses. 
the EPA-funded Social Indicators Planning and Evaluation System project (see Prokopy et al. 2008). Response options to these items included categorical options ranging from "never" to "always." Responses were grouped to form dichotomous dummy variables to enable logistic regression, with " 1 " indicating adoption of the BMP and " 0 " indicating non-adoption (i.e., responses indicating that respondents never use fertilizers or pesticides, or responses indicating that respondents always mulch, were coded as a "1"). Although individual survey questions were used to separately assess the frequency with respondents apply fertilizers and pesticides, these behaviors were so closely correlated that we combined them for analytical purposes (i.e., only individuals who never apply fertilizers and never apply pesticides were coded as a " 1 " in our dummy variable; those who indicated that they sometimes applied one or the other were coded as “0”). Our third dependent variable, which assessed respondents' willingness to support a municipal ban on lawncare chemicals, included five categorical response options (ranging from "not willing at all" to "very willing"). Like the BMP dependent variables, responses to this survey item were similarly transformed into a dichotomous dummy variable, with respondents indicating that they were "quite willing" or "very willing" to support a municipal lawncare chemical ban were coded as a " 1 " (and all others a “0”).

Independent variables were comprised of RAA components, including attitudes, descriptive and injunctive social norms, and perceived behavioral control, which were operationalized by the scale items described in Table 1 . Wording for these latter items were modeled after items included in prior urban stormwater survey research in other municipalities (e.g. Brehm et al. 2013; Gao et al. 2016) and consistent with the RAA (see Fishbein and Ajzen, 2010). Chronbach's $\alpha$ values ranged from 0.849 to 0.895 for all scales, indicating good reliability. The attitudinal component of the RAA (reported as Attitudes in the logistic regression results) was comprised of a 6-item summed scale of respondents' beliefs about the outcomes of adopting lawncare BMPs (reported as Beliefs in Table 1), weighted by how important each of these outcomes was perceived to be (reported as Attitudes in Table 1). The variables Social Norms-descriptive and Social Norms-injunctive were made up of 3-item summed scales indicating the degree to which respondents see friends, neighbors, and people in their neighborhood adopting lawncare BMPs (i.e. descriptive), and the degree to which respondents believe that these entities think respondents should adopt lawncare BMPs (i.e. injunctive), respectively. These were weighted by the stated degree to which these social entities (friends, neighbors, etc.) influence respondents' lawncare behavior (reported as Social Norms-influence in Table 1). Perceived Behavioral Control was created as a summed-scale of four items indicating the perceived ease (or difficulty) of adopting lawncare BMPs. 
Table 1. Scale items, measurement, and reliability used to form independent variables used in regression models.

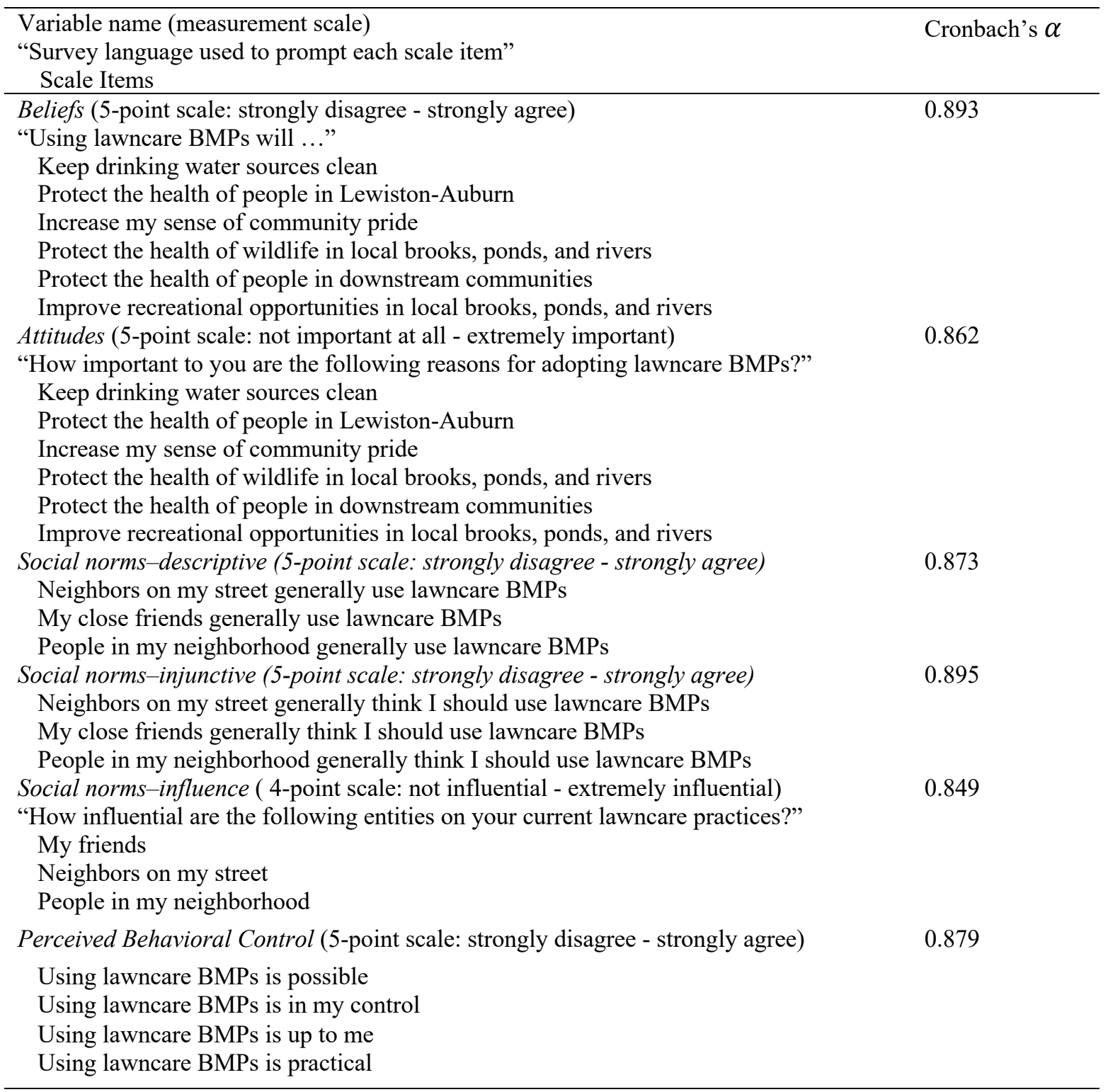

The variable age was included as a continuous variable, and gender was included as a dichotomous variable, with $1=$ female. College education was made into a dummy dichotomous variable indicating that a respondent had completed a 4-year college degree or more. Property ownership was used as a binary variable to distinguish homeowners $(=1)$ from renters $(=0)$. Property size was measured as a continuous variable, in hectares.

Survey Distribution

A 32-question survey was distributed to a random sample of Lewiston-Auburn residents in April and May

2018. Since the multifamily housing units in the cities' built-up downtown neighborhoods contain almost no yard space, households were selected from among census tracts of the city most likely to contain lawns (i.e. all tracts 
containing $25 \%$ or more pervious surface coverage). Surveys were distributed via the drop-off/pick-up method, which involves going door-to-door and recruiting potential participants in-person, leaving a survey with respondents who agree to participate, and then returning at an agreed-upon time to collect the completed survey. This method has been extensively field-tested in urban areas and has been shown to produce significantly higher response rates than other recruitment methods (e.g. mail, online, or intercept approaches), which reduces error associated with nonresponse (or nonrandom response) bias (Trentelman et al. 2016). Four trained survey administrators knocked on doors between 4pm and 8pm Monday-Friday and 9am-11am Saturday mornings. When contact was made at any given address, survey administrators introduced themselves and their Bates affiliation, briefly explained the purpose of the survey, and asked two screening questions. If the resident was an adult and had at least some say in lawn-care decisions (regardless of whether or not they actually performed the actual lawn care), the administrator requested that the resident take the survey. If no one answered the door, administrators made up to two additional contact attempts, varying the time of day that each subsequent attempt was made so as to maximize the chance that potential respondents would be home. If a resident answered the door but refused, the address was marked as such and no further contacts were made. If the resident agreed, the administrator left a paper copy of the survey, a manila envelope and plastic bag, and then agreed upon a time (typically the next day) for the administrator to return to pick up the completed survey, which respondents could hang in the envelope outside their front door. If a respondent was unable to complete a survey by the agreed-upon time, administrators returned as many times as necessary until the survey was completed or the respondent changed their mind and refused to participate.

Attempts were made to contact a random sample of 500 residential addresses in Lewiston and Auburn who in lower-density census tracts most likely to have lawns (defined as all census tracts with an average pervious surface coverage of $25 \%$ or greater). Of those 500 addresses, 261 were successfully contacted, resulting in a contact rate of $52.2 \%$. Of the 261 contacted, 200 completed a usable survey and 61 refused to participate, producing an overall survey response rate of $76.6 \%$. This response rate is exceptionally high, minimizes the chance of nonresponse bias, and indicates a high degree of confidence in the results reported below. Although the contact rate was lower than the response rate, contact rates are less likely than response rates to introduce systematic bias into the results. This is because the uncontacted portion of the sample was unaware of the survey and thus was unable to opt in or opt out of participation, and because we varied the days and times of contact attempts. This minimizes the likelihood that uncontacted residents are meaningfully different from contacted residents. 


\section{Data Management and Analysis}

Completed surveys were entered into Qualtrics, an online survey management system. Data were exported, cleaned in MS Excel, and uploaded to SPSS 24 for analysis. Descriptive statistics were generated, and linear logistic regression models were developed and run to test the significance and effect sizes of eight independent variables on each of the four dependent variables.

\section{Results}

Table 2 displays descriptive statistics for survey responses. The mean age of respondents was 57 , which is somewhat higher than the 2010 US Census estimates for the census tracts that align most closely with our study area. This is unsurprising given the fact that survey administrators limited potential respondents to adults in the household who have some amount of influence over lawn management practices. Just under half (48\%) of our respondents identified as female, and 30\% had earned a college education or higher. The vast majority of respondents (93\%) owned the property at which we contacted them, which averaged 0.41 ha (1.01 ac) in size. These numbers are consistent with ownership and parcel data for the more suburban and rural extents of Lewiston and Auburn.

Table 2. Descriptive statistics for dependent and summed-scale independent variables

\begin{tabular}{|c|c|c|c|c|}
\hline Variable & Scale & Mean & SD & $\mathrm{N}$ \\
\hline \multicolumn{5}{|l|}{ Dependent } \\
\hline Fertilizer + pesticide avoidance & 0-1 (1=adopt BMP) & 0.59 & 0.49 & 216 \\
\hline Mulching BMP adoption & $0-1$ (1=adopt BMP) & 0.63 & 0.48 & 216 \\
\hline Chemical ban support & $0-1$ (1=support ban $)$ & 0.58 & 0.49 & 154 \\
\hline \multicolumn{5}{|l|}{ Independent } \\
\hline Beliefs \& Attitudes & $0-120(120=$ most positive $)$ & 76.7 & 25 & 215 \\
\hline Social norms-descriptive & $0-45(45=$ strongest norm $)$ & 9.68 & 2.2 & 226 \\
\hline Social norms-injunctive & $0-45$ (45=strongest norm $)$ & 20.1 & 2.2 & 218 \\
\hline PBC & $4-20(20=$ most agreement $)$ & 15.6 & 3.2 & 219 \\
\hline College education & $0-1(1=$ college ed or more $)$ & 0.30 & 0.46 & 220 \\
\hline Gender & $0-1$ (1=female $)$ & 0.48 & 0.50 & 210 \\
\hline Age & $24-92$ & 57.1 & 15.8 & 206 \\
\hline Property ownership & $0-1$ (1=owns property) & 0.93 & 0.26 & 187 \\
\hline Property size (ha) & $0.11-14.8$ & 0.41 & 0.13 & 160 \\
\hline
\end{tabular}

$\mathrm{PBC}=$ Perceived Behavioral Control

As indicated in Table 3, beliefs about the outcome of adopting stormwater BMPs were more positive than negative, with substantially more agreement than disagreement that using lawncare BMPs will: keep drinking water sources clean; protect the health of wildlife in local brooks, ponds, and streams; protect the health of people in Lewiston/Auburn; protect the health of people in downstream communities; increase the recreational opportunities in local brooks, ponds, and streams ; and increase respondents' sense of community pride. Respondents' attitudes about the importance of these outcomes demonstrated a similarly broad consensus about the importance of each of 
these outcomes, with the average respondent indicating that these outcomes are, at minimum, important. .

Cumulatively, these responses indicate general agreement that these outcomes are important and that adopting

lawncare BMPs will lead to these outcomes (as indicated in the weighted "Attitudes \& Beliefs" variable in Table 2).

Table 3. Descriptive statistics for individual scale items in key summed-scale independent variables

\begin{tabular}{|c|c|c|c|c|}
\hline $\begin{array}{l}\text { Variable name } \\
\text { "Survey language used to prompt each scale item" } \\
\text { Scale item }\end{array}$ & Scale & Mean & SD & $\mathrm{N}$ \\
\hline Beliefs & $1-5$ (5=strongly agree) & & & \\
\hline \multicolumn{5}{|l|}{ "Using lawncare BMPs will ..." } \\
\hline Keep drinking water sources clean & & 4.08 & 0.84 & 229 \\
\hline Protect the health of people in Lewiston-Auburn & & 4.03 & 0.81 & 228 \\
\hline Increase my sense of community pride & & 3.42 & 0.79 & 228 \\
\hline Protect the health of wildlife in local brooks \& ponds & & 4.02 & 0.81 & 229 \\
\hline Protect the health of people in downstream communities & & 3.93 & 0.78 & 228 \\
\hline Improve recreational opportunities in local brooks \& ponds & & 3.76 & 0.92 & 229 \\
\hline Attitudes & $0-4$ (4=very important) & & & \\
\hline \multicolumn{5}{|l|}{$\begin{array}{l}\text { "How important to you are the following reasons for adopting } \\
\text { lawncare BMPs?" }\end{array}$} \\
\hline Keep drinking water sources clean & & 3.57 & 0.74 & 225 \\
\hline Protect the health of people in Lewiston-Auburn & & 3.31 & 0.92 & 224 \\
\hline Increase my sense of community pride & & 2.78 & 1.12 & 223 \\
\hline Protect the health of wildlife in local brooks and ponds & & 3.21 & 0.93 & 225 \\
\hline Protect the health of people in downstream communities & & 3.20 & 0.92 & 222 \\
\hline Improve recreational opportunities in local brooks \& ponds & & 3.11 & 0.97 & 223 \\
\hline Social norms-descriptive & $1-5$ (5=strongly agree) & & & \\
\hline Neighbors on my street generally use lawncare BMPs & & 3.22 & 0.86 & 229 \\
\hline My close friends generally use lawncare BMPs & & 3.32 & 0.80 & 228 \\
\hline People in my neighborhood generally use lawncare BMPs & & 3.19 & 0.86 & 227 \\
\hline Social norms-injunctive & $1-5$ (5=strongly agree) & & & \\
\hline $\begin{array}{l}\text { Neighbors on my street generally think I should use } \\
\text { lawncare BMPs }\end{array}$ & & 2.72 & 0.79 & 221 \\
\hline $\begin{array}{l}\text { My close friends generally think I should use lawncare } \\
\text { BMPs }\end{array}$ & & 2.88 & 0.88 & 220 \\
\hline $\begin{array}{l}\text { People in my neighborhood generally think I should use } \\
\text { lawncare BMPs }\end{array}$ & & 2.76 & 0.75 & 218 \\
\hline Social norms-influence & $0-3$ (3=very influential) & & & \\
\hline "How influential are the following entities on your current & & & & \\
\hline My friends & & 1.37 & 1.16 & 222 \\
\hline Neighbors on my street & & 1.11 & 1.24 & 221 \\
\hline People in my neighborhood & & 1.07 & 1.24 & 221 \\
\hline Perceived Behavioral Control & $1-5$ (5=strongly agree) & & & \\
\hline Using lawncare BMPs is possible & & 3.95 & 0.89 & 219 \\
\hline Using lawncare BMPs is in my control & & 3.94 & 0.99 & 220 \\
\hline Using lawncare BMPs is up to me & & 3.99 & 0.93 & 220 \\
\hline Using lawncare BMPs is practical & & 3.70 & 0.96 & 220 \\
\hline
\end{tabular}

Regarding social norms, respondents reported slightly more agreement than disagreement that they observe others (i.e. friends, neighbors, people in their neighborhood) using BMPs, and slightly more disagreement than agreement with injunctive perceptions of whether these people (i.e. friends, neighbors) think respondents should use BMPs (Table 3). However, significantly fewer respondents both reported observing others using lawncare BMPs 
and indicated that these same entities influence respondents' own lawncare behavior, as indicated by the weighted variable "Social norms-descriptive" in Table 2. Regarding injunctive norms weighted by the influence of others, just under half of respondents reported both being influenced by friends, neighbors, and others in the neighborhood and indicated that these entities think respondents should use BMPs, as indicated by the weighted variable "Social norms-injunctive" in Table 2.

On average, respondents reported agreement with statements indicating perceived behavioral control (Table 3). Regarding our three dependent variables, approximately two thirds of respondents stated that they do not use chemical fertilizers on their lawn (68\%) and regularly mulch their grass clippings while mowing (63\%), while just over half (58\%) indicated that they were quite willing or very willing to support a ban on the use of lawncare chemicals.

Table 4. Logistic regression models predicting adoption of BMPs and support for a chemical ban

\begin{tabular}{|c|c|c|c|c|c|c|c|c|c|}
\hline \multirow[t]{3}{*}{$\begin{array}{l}\text { Independent } \\
\text { variables }\end{array}$} & \multicolumn{9}{|c|}{$\begin{array}{l}\text { Dependent } \\
\text { variables }\end{array}$} \\
\hline & \multicolumn{3}{|c|}{ Fertilizer/pesticide avoidance } & \multicolumn{3}{|c|}{ Mulching BMP } & \multicolumn{3}{|c|}{ Chemical ban support } \\
\hline & $\mathrm{B}$ & SE & OR & $\mathrm{B}$ & SE & $\mathrm{OR}$ & $\mathrm{B}$ & $\mathrm{SE} \quad \mathrm{O}$ & OR \\
\hline Beliefs \& Attitudes & 0.010 & 0.010 & 1.010 & $0.027^{*}$ & 0.011 & 1.027 & $0.048^{* *}$ & 0.013 & 1.049 \\
\hline SN-descriptive & $0.220^{* *}$ & 0.086 & 1.247 & -0.001 & 0.077 & 0.999 & 0.046 & 0.900 & 1.047 \\
\hline SN-injunctive & $-0.114^{* *}$ & 0.038 & 0.892 & -0.023 & 0.034 & 0.977 & -0.032 & 0.041 & 0.968 \\
\hline $\mathrm{PBC}$ & $0.231^{*}$ & 0.093 & 1.260 & $0.207^{*}$ & 0.091 & 1.23 & 0.082 & 0.101 & 1.085 \\
\hline College ed & -0.403 & 0.442 & 0.669 & -0.289 & 0.466 & 0.749 & -0.915 & 0.536 & 0.401 \\
\hline Gender & $0.994^{*}$ & 0.415 & 0.370 & -0.087 & 0.428 & 0.917 & -0.468 & 0.487 & 0.626 \\
\hline Age & 0.004 & 0.013 & 1.004 & $-0.032^{*}$ & 0.014 & 0.968 & 0.000 & 0.016 & 1.000 \\
\hline Prop own & 0.960 & 1.030 & 2.612 & $-2.66^{*}$ & 1.245 & 0.070 & -0.587 & 0.973 & 0.556 \\
\hline Constant & -4.384 & 1.614 & 0.012 & -0.410 & 1.728 & 1.682 & -3.203 & 1.759 & 0.041 \\
\hline $\mathrm{N}$ & 133 & & & 133 & & & 98 & & \\
\hline$p^{2}$ & $30.346^{* * *}$ & & & $28.291^{* *}$ & & & $28.202^{* *}$ & & \\
\hline $\mathrm{R}^{2}$ & 0.273 & & & 0.263 & & & 0.334 & & \\
\hline Log likelihood & 153.120 & & & 144.480 & & & 107.001 & & \\
\hline
\end{tabular}

${ }^{*} \mathrm{p}<0.05, * * * \mathrm{p}<0.01$

$\mathrm{B}=$ coefficient, $\mathrm{SE}=$ Standard error, $\mathrm{OR}=$ Odds ratio, $\mathrm{R}^{2}=$ Nagelkerke $\mathrm{R}^{2}$

$\mathrm{SN}=$ Social norms (weighted by influence), $\mathrm{PBC}=$ Perceived behavioral control

All three logistic regression models were significant predictors of their respective dependent variable, with 133 respondents ( $55 \%$ of total sample) answering all of the independent variable questions, fertilizer/pesticide avoidance and mulching questions, and 98 respondents ( $40 \%$ of total sample) answering all independent variable and support for a ban on lawncare chemical chemicals questions (Table 4). For the fertilizer/pesticide avoidance model, perceived behavioral control $(\mathrm{p}<0.05)$, descriptive social norms $(\mathrm{p}<0.01)$ and identifying as female ( $\mathrm{p}$ $<0.05)$ were significant positive predictors of fertilizer/pesticide avoidance. Injunctive social norms were a significant negative predictor at the $\mathrm{p}<0.01$ level. Beliefs \& Attitudes towards BMP outcomes, having a college 
education, age, and property ownership were not significant. For the mulching BMP model, the Beliefs \& Attitudes variable $(\mathrm{p}<0.05)$ and PBC $(\mathrm{p}<0.05)$ were significant positive predictors of mulching. Age and property ownership were significant negative predictors of mulching at the $\mathrm{p}<0.05$ level. Injunctive and descriptive social norms, gender, and having a college education were not significant. In the final model, the Beliefs \& Attitudes variable was the only significant predictor of supporting a lawncare chemical ban. Descriptive and injunctive social norms, perceived behavioral control, gender, age, and property ownership were not significant.

\section{Discussion}

In light of the increasing contributions of urban and suburban stormwater runoff - particularly from lawns - as a source of nonpoint source water pollution, this study sought to investigate factors associated with residential actors' adoption of lawncare BMPs. We used Fishbein and Ajzen's (2010) Reasoned Action Approach to construct and test models predicting lawncare BMP adoption and support for a municipal policy that would ban lawncare chemicals. Overall, we found that perceived behavioral control is a key factor, positively predicting three out of four BMP adoptions with high levels of significance. This is consistent with the literature (e.g. Gao et al. 2018) showing residents who perceive fewer barriers and more control over their behavior - i.e. lawn-management practices - are more likely to adopt such practices. This also aligns with behavioral theories more broadly, and the RAA specifically, which demonstrates positive associations between individuals' perceptions of their ability to carry out behaviors and their intentions to and/or actual adoption of said behaviors (Fishbein and Ajzen 2010).

Likewise, we found that descriptive social norms hold predictive significance for fertilize -and pesticide avoidance. That is, respondents who said their friends, neighbors, and people in their neighborhood avoid fertilizers/pesticides were more likely to themselves avoid such use. This is consistent with previous scholarly work establishing a positive link between BMP adoption and social norms (Robbins 2012; Suh et al. 2016) and the potentially influential role of neighborhood homeowner associations in setting written and unwritten lawncare expectations (Fraser et al. 2013). However, we observed that injunctive social norms were negatively associated with fertilizer and pesticide avoidance (although they were not significant factors in models predicting mulching or support for a chemical ban). That is, respondents who reported relatively stronger perceptions that friends, neighbors, and people in their neighborhood think they ought to adopt lawncare BMPs were less likely to indicate that they had in fact avoided fertilizer and pesticide use. Although the effect sizes were small in both models where injunctive social norms were statistically significant, the negative association runs counter to what behavioral theory would predict. Follow-up studies - particularly qualitative and phenomenological methods, such as the conceptual 
and interview-based approach of Harris et al. (2013) - in this and other communities are clearly needed to verify whether our findings are anomalous and, if not, to uncover reasons that explain what we observed.

Beliefs and attitudes towards the outcome of BMP adoption were positive predictors of whether or not respondents mulched, and whether or not they supported a municipal ban on lawncare chemicals. That is, respondents who agreed that lawncare BMPs achieve positive social-ecological outcomes and indicated that these outcomes are important to them were more likely to mulch and support a municipal lawncare chemical ban. This aligns with what the RAA theory (Fishbein and Ajzen 2010) predicts. However, unlike social norms and perceived behavioral control, attitudes towards the outcome of fertilizer and pesticide avoidance were not significant predictive factors of fertilizer and pesticide avoidance. This may be due to the relative lack of variation in our dependent variables $\mathrm{s}$ - a much larger share of respondents indicated that they avoid fertilizer/pesticide use compared to the share who reported mulching - and a similar lack of variation in beliefs about the social-ecological impacts of lawncare BMP adoption. Both of these causes would be amplified by our relatively small sample size.

In terms of demographics, we observed few consistent predictors of BMP adoption. Although women were more likely than men to report avoiding fertilizer and pesticide use, gender was not a significant predictor of mulching or support for a municipal lawncare chemical ban. In our results, respondents with a college degree or more were less likely to support a municipal lawncare chemical ban, but level of education was otherwise not a significant predictor of BMP adoption. This was consistent with McCann and Shinn (2018) and Brehm et al. (2013), who found mixed results or no significant relationships between education level and BMP adoption, but inconsistent with Gao et al. (2016) and Newburn et al. (2014), who found positive associations between level of education and BMP adoption. Finally, in our results Respondent age and owning property (as opposed to renting) were negatively associated with mulching, but not significant predictors of any other dependent variables s of interest. These latter findings are surprising considering previous studies repeatedly reported positive relationships between homeownership and BMP adoption (Gao et al. 2016; Maeda 2017; Maeda et al. 2018). One possible explanation for the negative relationship between homeowner status and mulching is that renters may be more likely than homeowners to have a lawncare service company cut their lawn, and if these companies bag their grass clippings as a matter of policy, this might explain the result we observed. We note, however, that this is an unsubstantiated hypothesis that warrants further investigation.

Limitations of our study include our relatively small sample size, which limits the number of variables we can reliably test in our models. Coupled with the fact that our sample was drawn from two small adjacent cities (as opposed to cities in multiple geographic areas and sizes), this may limit the regional generalizability of our findings. 
Additional limitations include tradeoffs associated with the breadth of behaviors we attempted to measure. In our case, the RAA components (and multiple scale items) we used as attitudinal, social norm, and PBC variables in our models were used to predict four distinct dependent variables, which necessitated some degree of generalizable aggregation. For example, instead of asking a lengthy suite of attitudinal questions specifically about the socialecological impacts of fertilizer use and another batter specifically about impacts of pesticide use, we framed our scale questions around the aggregated concept of "lawncare BMPs" (with an accompanying definition that this entailed mulching, fertilizer and pesticide avoidance, etc.). Although there is methodological (and financial) expediency in using a single survey to measure and predict multiple behaviors --and although this approach is extremely common in applied environmental social science research -- this nevertheless may have weakened our models' predictive power. Having acknowledged all of this, our high response rate underscores the quality of our data and lends credibility to the local generalizability of our findings.

\section{Conclusions}

Our study presents insights into factors affecting stormwater BMP adoptions among urban/suburban households in central Maine, USA. We applied the Reasoned Action Approach (Fishbein and Ajzen 2010), a behavioral theory that has been widely applied in various socio-environmental systems but that has not, to our knowledge, been applied in the context of urban/suburban stormwater management and lawncare BMP adoption. Overall, we found mixed support for the predictive capability of the RAA in our study's geographic and behavioral context, and no consistent predictors of BMP adoption of support for a chemical ban. Perceived behavioral control emerged as a consistent, significant predictor of lawncare BMP adoption. Descriptive social norms were significant, positive predictors of fertilizer and pesticide avoidance, and attitudes towards the outcome of BMP adoption had similarly positive and significant effects on the likelihood that respondents mulched and supported a municipal ban on lawncare chemicals. Injunctive social norms were significant negative predictors of BMP adoption, although they explained a relatively small proportion of our models' variation. Respondents' demographic characteristics, including gender, age, level of education, and property ownership, also emerged as significant in our models, but were not consistently significant across BMPs and support for a chemical ban. Our findings suggest that outreach and educational materials and campaigns designed to influence the lawncare behavior of individual urban/suburban residents may benefit from emphasizing not only the potentially desirable outcomes of adopting stormwater-friendly BMPs (i.e. attitudinal dimensions), but also the ease and straightforwardness of doing so (i.e. PBC dimensions). Likewise, such efforts may benefit from activating individuals' response to local social norms. For example, flyers 
or demonstration events could highlight recognizable individuals in a given neighborhood that have committed to adopting stormwater-friendly BMPs, and/or could highlight the proportion of residents in a neighborhood that have decided to forgo pesticides and fertilizers (including how this proportion has grown over time, if known).

This research used the RAA to predict the behavior of individuals, since the current paradigm of stormwater management in this study's context relies on approaches that target behavior change at the level of individual actors. Indeed, this approach is increasingly common in U.S. urban environments that are governed by the US EPA's requirements for communities with municipally separated stormwater and sewer systems. However useful it may be to understand such individual-level determinants of behavior, we recognize the importance of broader structural factors that also influence individual behavior, which in some cases may eclipse the RAA's components in terms of overall impact on behavior at broader geographic scales. These broader elements include homeowner covenants that stipulate or subtly influence social norms at the neighborhood scale (Fraser et al. 2013), as well as the increasingly powerful ecosystem of lawncare and chemical companies that use persuasive and pervasive marketing campaigns to shape attitudes and norms (Robbins 2012), and to fight municipal chemical bans (Lerner 2018). Future research, therefore, would benefit from developing questions and constructs capable of capturing these underlying factors, and from evaluating the efficacy of programmatic and regulatory alternatives that move beyond the US EPA's current reliance on individuals' voluntary adoption of BMPs.

\section{References}

Androscoggin River Watershed Council (2016). Androscoggin River (AWRC) 2016 Data Report. Retrieved from the Maine Department of Environmental Protection: https://www.maine.gov/dep/water/monitoring/rivers_and_streams/vrmp/reports/2016/ARWC_2016\%20Re port.pdf 
Brehm, J.M., Pasko, D.K., Eisenhauer, B.W. (2013). Identifying Key Factors in Homeowner's Adoption of Water Quality Best Management Practices. Environmental Management, 52:113-122. doi:10.1007/s00267-0130056-2

Brown, R.R., Farrelly, M.A. (2009). Delivering sustainable urban water management: a review of the hurdles we face. Water Science and Technology, 59:839-846. doi:10.2166/wst.2009.028

Brown, R.R., Farrelly, M.A., Loorbach, D.A. (2013). Actors working the institutions in sustainability transitions: The case of Melbourne's stormwater management. Global Environmental Change, 23:701-718. doi:10.1016/j.gloenvcha.2013.02.013

Busse, R., Ulrich-Schad, J.D., Crighton, L., Peel, S., Genskow, K., Prokopy, L.S. (2015). Using Social Indicators to Evaluate the Effectiveness of Outreach in Two Indiana Watersheds. Journal of Contemporary Water Research \& Education, 156:5-20. doi:10.1111/j.1936-704X.2015.03200.x

Dietz, M.E., Clausen, J.C., Filchak, K.K. (2004). Education and changes in residential nonpoint source pollution. Environmental Management, 34:684-690 https://doi.org/10.1007/s00267-003-0238-4

Fishbein, M., Ajzen, I. (2010). Predicting and changing behavior: the reasoned action approach. New York: Psychology Press.

Fraser, J.C., Bazuin, J.T., Band, L.E., Grove, J.M. (2013). Covenants, cohesion, and community: The effects of neighborhood governance on lawn fertilization. Landscape and Urban Planning, 115:30-38. doi:10.1016/j.landurbplan.2013.02.013

Gao, Y., Babin, N., Turner, A.J., Hoffa, C.R., Peel, S., Prokopy, L.S. (2016). Understanding urban-suburban adoption and maintenance of rain barrels. Landscape and Urban Planning, 153:99-110. doi:10.1016/j.landurbplan.2016.04.005

Gao, Y., Church, S.P., Peel, S., Prokopy, L.S. (2018). Public perception towards river and water conservation practices: Opportunities for implementing urban stormwater management practices. Journal of Environmental Management, 223:478-488. doi:10.1016/j.jenvman.2018.06.059

Harris, E.M., Martin, D.G., Polsky, C., Denhardt, L., Nehring, A. (2013). Beyond "Lawn People”: The Role of Emotions in Suburban Yard Management Practices. The Professional Geographer, 65:345-361. doi:10.1080/00330124.2012.681586

Hayden, L.M. (2014). Best Management Practices for Reducing Residential Landscape Runoff and Non-Point Source Pollution: An Investigation of the Effects of Outreach Education and Aesthetic Preferences on 
Homeowner Behavior. (Master's thesis, University of California, Davis). Available from ProQuest

Dissertations Publishing. (Order No. 1569779).

Hoffa, C.R., Babin, N., Turner, A.J. (2014). Adoption, Maintenance and Diffusion of Stormwater Best Management Practices: Rain Barrels. Retrieved from https://docs.lib.purdue.edu/surf/2014/presentations/10

Hottenroth, D., Harper, C., Turner, J. (1999). Effectiveness of integrated stormwater management in a Portland,

Oregon, watershed. Journal of the American Water Resources Association, 35:633-641.

doi:10.1111/j.1752-1688.1999.tb03619.x

Judd, R.W. (1990). The coming of the clean waters acts in Maine, 1941-1961. Environmental History Review, 14(3), $50-73$.

Lerner, S. (2018). How a ragtag group of oregon locals took on the biggest chemical companies in the world -- and won. The Intercept. Retrieved from https://theintercept.com/2018/09/15/oregon-pesticides-aerial-spray-ban/

Leslie, M. (2015) Increasing environmental knowledge and effecting change in lawn maintenance behavior among homeowners. (Master's thesis, University of Minnesota). Retrived from http://hdl.handle.net/11299/177033

Maeda, P.K. (2017). Knowledge, Attitudes, and Implementation of BMPs and Mosquito Management across a Socioeconomic Gradient. (Master's thesis, University of Maryland). Retrieved from https://doi.org/10.13016/M2057CT9P

Maeda, P.K., Chanse, V., Rockler, A., Montas, H., Shirmohammadi, A., Wilson, S., Leisnham, P.T. (2018). Linking stormwater Best Management Practices to social factors in two suburban watersheds. PloS ONE 13(8): e0202638. doi:10.1371/journal.pone.0202638

Martini, N.F., Nelson, K.C. (2015). The role of knowledge in residential lawn management. Urban Ecosystems, 18:1031-1047. doi:10.1007/s11252-014-0415-7

McCann, L., Shin, D.W. (2018). Household Use of Composted Manure and Phosphorous-Free Fertilizers: Feeling Good versus Doing Good. Journal of Environmental Protection, 9:140-157. doi:10.4236/jep.2018.92011

Milesi, C., Running, S. W., Elvidge, C. D., Dietz, J. B., Tuttle, B. T., \& Nemani, R. R. (2005). Mapping and modeling the biogeochemical cycling of turf grasses in the United States. Environmental Management, $36(3), 426-438$.

National Research Council. (2009). Urban stormwater management in the United States. Washington, DC: National Academies. 
Newburn, D.A., Alberini, A., Rockler, A., Karp, A. (2014). Adoption of Household Stormwater Best Management Practices. University of Maryland Extension. Retrieved from http://hdl.handle.net/1903/14974

Persaud, A., Alsharif, K., Monaghan, P., Akiwumi, F., Morera, M.C., Ott, E. (2016). Landscaping practices, community perceptions, and social indicators for stormwater nonpoint source pollution management. Sustainable Cities and Society, 27:377-385. doi:10.1016/j.scs.2016.08.017

Prokopy, L., Floress, K., Klotthor-Weinkauf, D., Baumgart-Getz, A. (2008). Determinants of agricultural best management practice adoption: Evidence from the literature. Journal of Soil and Water Conservation, 63(5):300-311. doi:10.2489/jswc.63.5.300

Rissman, A.R., Carpenter, S.R. (2015). Progress on Nonpoint Pollution: Barriers and Opportunities. Daedalus, 144(3), 35-47.

Robbins, P. (2012). Lawn people: How grasses, weeds, and chemicals make us who we are. Philadelphia, PA: Temple University.

Shin, D.W., McCann, L. (2018a). Analyzing differences among non-adopters of residential stormwater management practices. Landscape and Urban Planning, 178:238-247. doi:10.1016/j.landurbplan.2018.06.003

Shin, D.W., McCann, L. (2018b). Enhancing Adoption Studies: The Case of Residential Stormwater Management Practices in the Midwest. Agricultural and Resource Economics Review, 47:32-65. doi:10.1017/age.2017.3

Suh, D.H., Khachatryan, H., Guan, Z. (2016). Why do we adopt environmentally friendly lawn care? Evidence from do-it-yourself consumers. Applied Economics, 48:2550-2561. doi:10.1080/00036846.2015.1125431

Trentelman, C.K., Irwin, J., Petersen, K.A., Ruiz, N., Szalay, C.S. (2016). The case for personal interaction: dropoff/pick-up methodology for durvey research. Journal of Rural Social Sciences, 31:68-104.

Turton, D.J., Smolen, M.D., Stebler, E. (2009). Effectiveness of BMPS in Reducing Sediment From Unpaved Roads in the Stillwater Creek, Oklahoma Watershed1. Journal of the American Water Resources Association, 45:1343-1351. doi:10.1111/j.1752-1688.2009.00367.x

U.S. Environmental Protection Agency (2017). Municipal Separate Storm Sewer System (MS4) Storm Water Management Program (SWMP). Retrieved from https:/www.epa.gov/tx/municipal-separate-storm-sewersystem-ms4-storm-water-management-program-swmp 